\title{
Diagnosis and treatment of chronic hepatitis B
}

\author{
Raymond D'Souza MRCP Graham R Foster PhD FRCP
}

J R Soc Med 2004;97:318-321

As the leading cause of cirrhosis and hepatocellular carcinoma, chronic hepatitis B virus (HBV) infection presents a massive economic burden. ${ }^{1}$ Here we review methods of diagnosis, prevention and treatment.

\section{PREVALENCE}

The highest prevalence areas for HBV infection $(>8 \%)$ are in African, Western Pacific and Asian countries where the virus is acquired mainly through perinatal transmission from the chronically infected mother or through infection in early childhood. ${ }^{2}$ Such early infections are responsible for most cases of hepatocellular carcinoma in these countries. In southern and eastern Europe, where prevalence is intermediate $(2-7 \%)$, infection is due to perinatal transmission, needle sharing among drug users, nosocomial transmission, tattooing and body piercing. In areas with low HBV endemicity $(<2 \%)$, which include Western Europe, North America and Australia, transmission is mainly through sexual contacts and needle sharing among drug users. $^{2}$ Universal hepatitis B vaccination programmes for infants and adolescents have begun to yield reductions in the prevalence of HBV infection. ${ }^{3}$

\section{NATURAL HISTORY}

The natural history of HBV infection is determined by the interplay between virus replication and host immune response. Box 1 lists the virus markers and their properties. Acute liver damage is caused mainly by the protective immune response, which destroys virus-infected liver cells. In the absence of an immune response sufficient to clear the virus, the infection becomes chronic. This is the case with perinatally acquired $\mathrm{HBV}$ infection, which tends to be clinically silent and evolves to chronicity in 95\% (Figure 1). ${ }^{4}$ Perinatal infection begins with an immunotolerant phase in which virus replication is high with little hepatic damage. ${ }^{5}$ In the laboratory this phase is identifiable by the serum virus markers HBsAg and HBeAg and HBV DNA; serum aminotransferases may be normal or slightly raised. It is succeeded, a variable time after infection, by a phase in

Digestive Disease Research Centre, Queen Mary's School of Medicine and Dentistry, Barts and The London NHS Trust, London, UK

Correspondence to: Professor Graham R Foster, DDRC, Royal London Hospital, Turner Street, London E1 2AD, UK which an immune response to the virus develops, with resultant liver damage that may progress to cirrhosis. This immunoactive phase is characterized by serum aminotransferase flares and suppression of viral replication (decline in serum HBV DNA). These flares may be associated with development of an antibody to $\mathrm{HBeAg}$, resulting in a low or non-replicative phase (serum $\mathrm{HBeAg}$ undetectable, anti-HBe present, very low serum HBV DNA, normal aminotransferases) in which the virus is suppressed by the host immune system. ${ }^{5}$ In some patients an immunoescape phase arises when the virus mutates to variants that do not express $\mathrm{HBeAg}$ (HbeAg negative chronic hepatitis). A proportion of these HBeAg-negative patients then show high HBV replication with progression of their liver disease. Some patients ultimately lose HBsAg and this final phase is referred to as resolution of infection.

Adults who are infected with HBV usually develop an acute hepatitis that resolves spontaneously. However, 3-5\% go on to develop chronic hepatitis $\mathrm{B}$ which then follows a similar pattern to perinatally acquired chronic $\mathrm{HBV}$ infection. ${ }^{5}$

\section{PREVENTION}

HBV transmission can be prevented by screening of donated blood, plasma, organ tissue and semen, by virus inactivation in plasma-derived products, by risk-reduction counselling and by implementation of infection control practices. However, the single most effective prevention measure is routine immunization for infants. ${ }^{3}$ Immunization should also be offered to high-risk individuals including healthcare workers, persons with multiple sex partners, intravenous drug users, patients with chronic diseases who are likely to undergo multiple percutaneous procedures and contacts of $\mathrm{HBV}$-infected persons. Babies born to $\mathrm{HBsAg}$ carrier mothers should be protected against perinatal transmission by administration of hepatitis $\mathrm{B}$ immunoglobulin and $\mathrm{HBV}$ vaccine. ${ }^{3}$

\section{Diagnosis}

The diagnosis of chronic HBV infection is made from its biochemical, virological and histological features together with exclusion of other causes such as HCV. ${ }^{6}$ Routine liver function tests and serological assays for the detection of $\mathrm{HBV}$ antigens (HBsAg and $\mathrm{HBeAg}$ ) and antibodies 


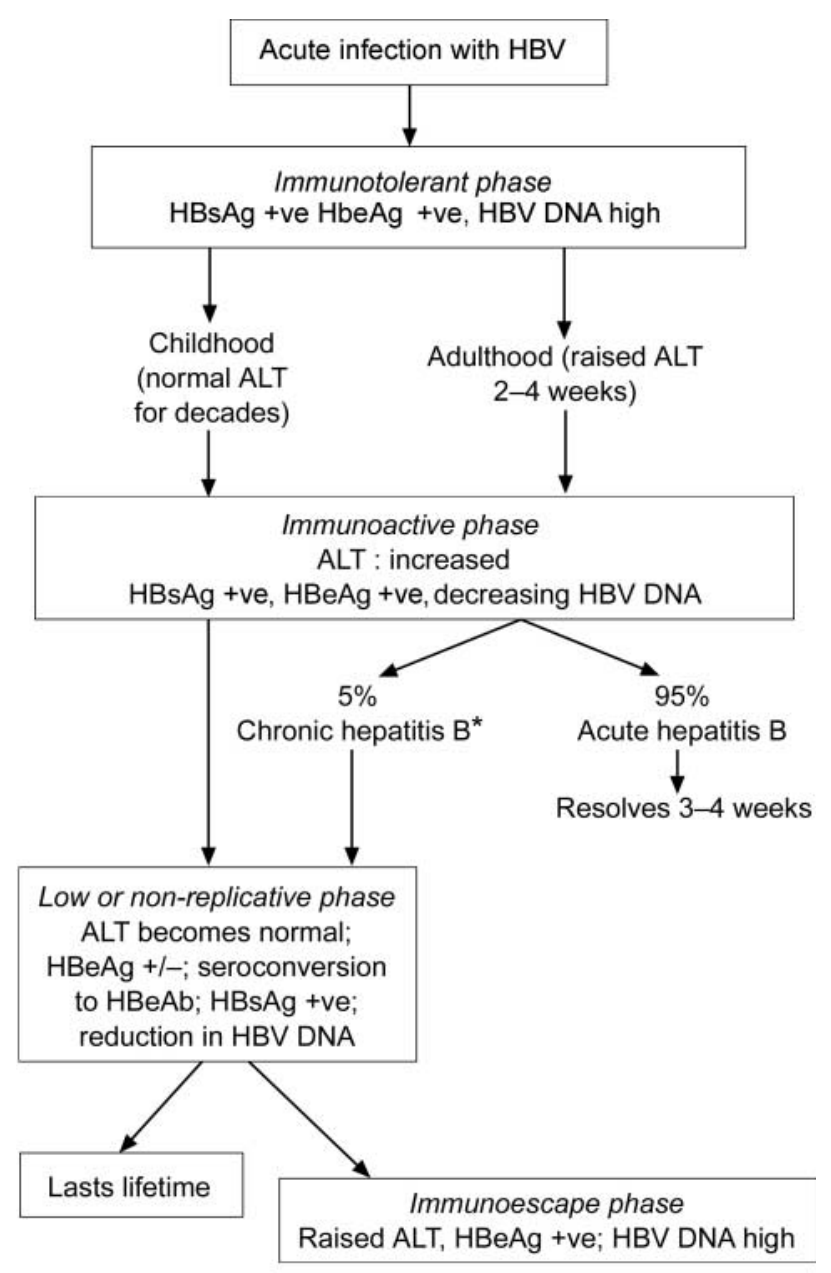

Figure 1 Natural history of HBV infection. *Adult chronic hepatitis B may revert to immunotolerant or the immunoactive phase

Box 1 HBV markers and their properties. ALT=alanine amino transferase

HBsAg: surface protein contained within the lipoprotein coat $\mathrm{HBsAb}$ : antibody to HBsAg, indicator of recovery/immunity to HBV infection

HBeAg: viral product secreted in blood, marker of infectivity, active replication (though absent in precore mutants) $\mathrm{HBeAb}$ : antibody to $\mathrm{HBeAg}$, denoting decreased infectivity HBcAg: core antigen (viral capsid), intracellular and not detected in serum

$\mathrm{HBcAb}$ IgM: antibody denoting recent HBV infection or exacerbation

HBcAb IgG: contamination marker, positive after HBV contact HBV DNA: quantitative indicator of virus in blood

(anti-HBs, anti-HBc and anti-HBe) should be performed to assess the phase of chronic hepatitis B. HBV DNA can be monitored in serum by means of DNA hybridization with signal amplification, to assess disease activity and candidacy for antiviral therapy and to determine response to treatment. Liver biopsy is essential to confirm the diagnosis, to identify any intercurrent disease affecting the liver, to stage the fibrosis and to grade the necroinflammation.

\section{TREATMENT}

The main goal of treatment of chronic hepatitis B is to suppress HBV replication and to induce remission of liver disease before development of cirrhosis and hepatocellular carcinoma. Recombinant subcutaneous interferon- $\alpha$ (10 MU thrice weekly) and oral lamivudine (100 mg once a day) are licensed for this use in many countries and oral adefovir (10 $\mathrm{mg}$ once a day) has recently been approved. Response to therapy is defined as undetectable HBV DNA $\left(<10^{5}\right.$ copies $/ \mathrm{mL}$ ) in serum, sustained loss of $\mathrm{HBeAg}$ with or without detection of anti-HBe (HBeAg seroconversion), and improvement in liver disease, normalization of aminotransferases and decrease in necroinflammation or fibrosis progression halted. ${ }^{5}$ Pretreatment factors predictive of response are similar for all three treatments and include high serum aminotransferases, low serum HBV DNA and pronounced necroinflammation on biopsy. ${ }^{6}$

The advantages of interferon include finite duration of treatment, lack of resistant mutants and durable response; disadvantages are high cost, the need for subcutaneous administration and the side-effects. ${ }^{7,8}$ Lamivudine is more economical and better tolerated but resistance may develop. ${ }^{9}$ With adefovir, an expensive drug, resistance is uncommon. ${ }^{10}$

Treatment is not recommended for patients with mild chronic hepatitis B because of the low efficacy of existing therapies, but these patients should be monitored.6,7,11 Who, then, should receive antiviral therapy? The American Association for the Study of Liver Disease ${ }^{7}$ recommends that patients who are $\mathrm{HBeAg-positive} \mathrm{with} \mathrm{moderate} \mathrm{or}$ severe chronic hepatitis and raised aminotransferases (more than twice the upper limit of normal) should be offered either: (i) a 4-6 month course of interferon (10 MU thrice weekly); or (ii) a 1-year course of lamivudine (100 mg once a day if no HIV infection); or (iii) a 1-year course of adefovir (10 $\mathrm{mg}$ once a day). Since the viral response to lamivudine or adefovir is not affected by previous failure with interferon, the European Association for Study of the Liver favours using interferon first. ${ }^{12}$ Interferon causes loss of $\mathrm{HBeAg}$ in $15-25 \%$ of patients which is sustained in $80 \%$ 1 year after treatment. ${ }^{8,13}$ Lamivudine gives $10-15 \%$ sustained seroconversion of $\mathrm{HBeAg}$ at 1 year and a virological response in nearly all, but unfortunately $60 \%$ of responders have relapsed 1 year after treatment. ${ }^{9,11}$ Drug resistance to lamivudine develops in $20 \%$ during the first year and increases to $60 \%$ at year $4 .{ }^{9,11}$ Adefovir yields a similar seroconversion rate to lamivudine but durability of response has not been yet established. ${ }^{10}$ Treatment with 
Table 1 American Association for the Study of Liver Disease recommendations for the treatment of chronic hepatitis B (modified from Ref. 7 by permission)

\begin{tabular}{|c|c|c|c|}
\hline HBeAg & HBV DNA & $A L T$ & Treatment strategy \\
\hline \multirow[t]{2}{*}{+} & + & $\leqslant 2 \times U L N$ & Low efficacy with current treatment \\
\hline & & & Observe: consider treatment when ALT becomes elevated \\
\hline \multirow[t]{8}{*}{+} & + & $>2 \times U L N$ & IFN- $\alpha$, LAM, or ADV may be used as initial therapy \\
\hline & & & Endpoint of treatment-seroconversion from HBeAg to anti-HBe \\
\hline & & & Duration of therapy \\
\hline & & & -IFN- $\alpha$ : 16 weeks \\
\hline & & & - Lamivudine: minimum 1 year, continue for 3-6 months after HBeAg seroconversion \\
\hline & & & - Adefovir: minimum 1 year \\
\hline & & & IFN- $\alpha$ non-responders/contraindications to IFN- $\alpha \rightarrow$ LAM or ADV \\
\hline & & & LAM resistance $\rightarrow$ ADV \\
\hline \multirow[t]{8}{*}{-} & + & $>2 \times U L N$ & IFN- $\alpha$, LAM or ADV may be used as initial therapy \\
\hline & & & $\begin{array}{l}\text { Endpoint of treatment-sustained normalization of ALT and undetectable HBV DNA by PCR } \\
\text { assay }\end{array}$ \\
\hline & & & Duration of therapy \\
\hline & & & - IFN- $\alpha: 1$ year \\
\hline & & & - Lamivudine: > 1 year \\
\hline & & & - Adefovir: > 1 year \\
\hline & & & IFN- $\alpha$ non-responders/contraindications to IFN- $\alpha \rightarrow$ LAM or ADV \\
\hline & & & LAM resistance $\rightarrow$ ADV \\
\hline- & - & $\leqslant 2 \times U L N$ & No treatment required \\
\hline \multirow[t]{2}{*}{ \pm} & + & Cirrhosis & Compensated: LAM or ADV \\
\hline & & & $\begin{array}{l}\text { Decompensated: LAM (or ADV); coordinate treatment with transplant centre. IFN- } \alpha \\
\text { contraindicated }\end{array}$ \\
\hline \multirow[t]{2}{*}{ \pm} & - & Cirrhosis & Compensated: Observe \\
\hline & & & Decompensated: Refer for liver transplant \\
\hline
\end{tabular}

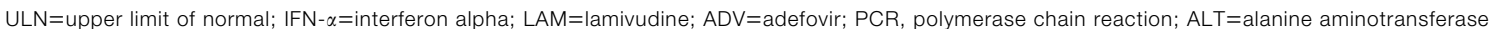

lamivudine and adefovir should be continued for 4-6 months after seroconversion has been achieved. ${ }^{12}$ If no seroconversion is seen after 1 year of oral medication the decision whether to continue treatment will be influenced by the costs (higher for adefovir) and the risk that drug resistance (higher for lamivudine) will develop.

Patients with HBeAg-negative disease who have high aminotransferases, moderate to severe hepatitis and HBV DNA $>10^{5}$ copies $/ \mathrm{mL}$ should be treated with interferon (for 1 year) with lamivudine or with adefovir. ${ }^{6,7}$ As with HBeAg-positive disease, the oral agents can be continued beyond 1 year in viral non-responders, subject to considerations of virus resistance and drug toxicity. ${ }^{12}$ If lamivudine resistant mutants emerge and HBV DNA and aminotransferases are low, one can continue lamivudine or stop it and monitor levels. An alternative is to switch to adefovir. ${ }^{12}$

Patients with compensated cirrhosis and raised HBV interferon can cause flares and should be avoided.6,7 Patients with low or undetectable HBV DNA should simply be observed. ${ }^{7}$ For decompensated cirrhosis with high viral loads lamivudine or adefovir should be continued until liver transplantation. ${ }^{7,12}$ Withdrawal of lamivudine demands adefovir back-up since it can lead to hepatic decompensation. ${ }^{14}$ If viral load is low or undetectable, patients should be referred directly for liver transplantation. ${ }^{12}$ Table 1 summarizes the US recommendations.

The ideal approach to antiviral therapy in chronic hepatitis B remains uncertain. In most patients monotherapy is insufficient to eradicate infection. Peginterferon alpha-2a is currently under evaluation and data from the phase II trials suggest a greater than twofold higher combined response rate (HBeAg loss, HBV DNA suppression and normalization of alanine aminotransferase) than with conventional interferon after 24 weeks. ${ }^{15}$ However, the key issue for the future will be the efficacy of combined and/or sequential treatment with oral agents and interferon. 
Note Professor Foster acts as a consultant to companies that market drugs for treatment of hepatitis B.

\section{REFERENCES}

1 Gay N, Edmunds W, Bath E, et al. Estimating the Global Burden of Hepatitis B. Geneva: World Health Organization, Department of Vaccines and Biologicals, 2001

2 Margolis HS, Alter MJ, Hadler SC. Hepatitis B: evolving epidemiology and implications for control. Semin Liver Dis 1991;11:84-92

3 Kane MA. Global status of hepatitis B immunisation. Lancet 1996;348:696

4 Sanchez-Tapias JM, Vilar JH, Costa J, et al. Natural history of chronic persistent hepatitis B. Relationship between hepatitis B virus replication and the course of the disease. J Hepatol 1984;1:15-27

5 Fattovich G. Natural history of hepatitis B. J Hepatol 2003;39:S50-8

6 Lok A, McMahon B. Chronic hepatitis B. Hepatology 2001;34:1225-41

7 Lok A, McMahon B. ASLD guidelines. Chronic hepatitis B: update of recommendations. Hepatology 2004;39:857-61
8 Craxi A, Bona DD, Camma C. Interferon alpha for HBeAg positive chronic hepatitis B: systematic review. J Hepatol 2003;39:S99-105

9 Lai CL, Chien RN, Leung NW, et al. A one-year trial of lamivudine for chronic hepatitis B. N Engl J Med 1998;339:61-8

10 Marcellin P, Chang TT, Lim SG, et al. Adefovir depivoxil for the treatment of hepatitis B e antigen positive chronic hepatitis B. $N$ Engl J Med 2003;348:808-16

11 Dienstag JL, Schiff ER, Wright TL, et al. Lamivudine as initial treatment for chronic hepatitis $\mathrm{B}$ in the US. $N$ Engl $\mathrm{J}$ Med 1999;341:1256-63

12 EASL Consensus Conference on Hepatitis B. J Hepatol 2003;39:S3-25

13 Lok AS, Chung HT, Liu VW, Ma OC. Long-term follow-up of chronic hepatitis B patients treated with interferon alfa. Gastroenterology 1993; 105:1833-8

14 Villeneuve JP, Condreay LD, Willems B, et al. Lamivudine treatment for decompensated cirrhosis resulting from chronic hepatitis B. Hepatology 2000;31:207-10

15 Cooksley WGE, Piratvisuth T, Wang Y, et al. $40 \mathrm{KDA}$ peginterferon alfa-2a (PEGASYS(r)): efficacy and safety results from a phase II, randomized, multicenter study in the treatment of $\mathrm{HBeAg}$ positive chronic hepatitis B. Hepatology 2001;34:349A 